\title{
SEEKING ANSWERS TO THE ADVANCED MOBILE SERVICES PARADOX
}

\author{
Minimal Acceptance and Use Despite Accessibility
}

\author{
Jennifer Blechar', Ioanna Constantiou ${ }^{2}$, Jan Damsgaard ${ }^{2}$ \\ 'University of Oslo, Norway; Copenhagen Business School, Denmark
}

\begin{abstract}
At a time when mobile service adoption rates remain much lower than anticipated, better understanding of users' behavior and attitude towards new technology becomes critical. This paper brings insights from behavioral economics to the technology acceptance research domain to investigate adoption of advanced mobile services. Through a field study of mobile service acceptance and use, we explore user behavior during the initial stages of technology adoption. We argue that in order to better understand the cognitive processes underlying technology acceptance or rejection decisions for advanced mobile services, the economic aspects of those processes must be considered. This is especially the case given the similarity of new mobite services to those currently available to consumers through other means and the inherent elements of substitution which exist therein:
\end{abstract}

Keywords: Technology Acceptance, Mobile Services, Mental Accounting

\section{INTRODUCTION}

As the prices on voice-based telephony steadily decrease, the mobile telecommunications industry is looking for new sources of revenue. Several of the key actors in the field have pinned their hopes on advanced mobile services such as news, weather forecasts, chat and map directories offered via mobile operators' proprietary platforms. However, in many western European countries mobile users have been reluctant to embrace these services let alone pay for them, while at the same time, sales of new mobile devices are increasing at an unprecedented pace. There seems to be a paradox; the new mobile devices can support various advanced services but 
users do not take the step of initiating and adopting them. In this paper we seek to better understand why users do not adopt new mobile services even when they are potentially readily available in the palm of their hand.

As many technologies mature they become domesticated and find their place in our everyday lives. For example the radio found its place, consumed a certain part of our time and became an important ingredient in our lives. When the TV came around in 1950's it challenged the position of the radio and part of the time dedicated to radio was substituted by TV. In the recent decade we have seen time spent on Internet related activities increasing at the expenses of the TV. Thus, with the adoption of a technology, use substitutes time spent on other activities. In our context, new advanced mobile services must challenge, compete and replace traditional mechanisms of getting access to news, weather forecasts, etc. It is this process we have not yet seen progress for in the mobile services arena.

In this paper we introduce the concept of mental accounting from the behavioral economics domain to technology acceptance in the mobile industry as an explanatory vehicle to investigate this lack of adoption of advanced mobile services. Mental accounting addresses the cognitive processes underlying users purchase and use decisions and offers the opportunity for a systematic investigation of choice processes. The next section briefly reviews existing related literature in the mobile services arena and introduces the concept of mental accounting. This is followed by an introduction to the conducted field study of new mobile service use among 36 mobile service users in Denmark. The discussion exploring the preliminary findings through the lens of mental accounting is then presented. Finally, we point to main insights generated and future research directions.

\section{LITERATURE INSIGHTS}

\subsection{Technology Acceptance in the Mobile Arena}

The study of technology adoption continues to be a popular topic of concern within the IS discipline. Traditional research in this domain is rooted in models and theories of technology acceptance such as the Technology Acceptance Model (Davis, 1989), The Theory of Planned Behavior (Ajzen, 1985, 1991), the Theory of Reasoned Action (Ajzen \& Fishbein, 1980), etc. As research within the mobile industry progresses, many of the models above have also been adopted and used to investigate the acceptance of new mobile services and other mobile applications (e.g. Hung et al., 2003; Khalifa \& Cheng, 2002). 
However, many of the services offered through mobile devices are available through existing technology, such as the Internet, thus evoking an element of substitution. This is an aspect not necessarily present in existing technology adoption studies where the above models have typically been applied. Many of the mobile services being offered today are free Internet services that have simply been transferred to the mobile device resulting in poorer quality with an expectation that the consumer will now be willing to pay for them. Finally many services only have value when a majority has adopted them due to network externalities (Katz \& Shapiro, 1992).

In order to more thoroughly explore technology acceptance of new mobile services, we argue, existing research must consider the economic aspect of technology adoption within the wider context of use. Choosing to pay for a novel mobile service also offered through the Internet, for example, can contain different motivational factors than making use of a required organizational program. In doing this, focus must be placed on the underlying cognitive elements fueling users choice and decision processes as well as the ongoing reflexivity present during the technology acceptance process (Blechar et al., 2005). As such, insights from the economics discipline seem to offer promise for the further exploration of potentially influential elements related to user choice and decision processes.

\subsection{Mental Accounting}

The concept of mental accounting comes from the behavioral economics domain and deals with the cognitive processes underlying consumer choices and decision behaviors (Thaler, 1980). It embarks from the neo-ciassical economic models by combining insights from psychology to the analysis of consumer's choices, thereby offering complimentary insights to existing technology acceptance research. It includes four main components that explain; how users perceive and experience the outcome of choice processes, the underlying cognitive processes influencing purchase decisions, the manner in which income is allocated to the purchase of various goods and the frequency with which consumers evaluate their income versus purchases (p. 183, Thaler, 1999). This is particularly useful in attempting to explain consumers' motives and decisions related to adoption of different products or services.

Thaler (1985) proposed a set of parameters for mental accounting. We focus on the two parameters related to the mobile services context that offer insight on mobile users' behavior, namely, transaction utility and payment decoupling. "Transaction utility measures the perceived value of a deal. It is defined as the difference between the amount paid and the 'reference price' for the product/service" (p. 188-189, Thaler, 1999). The latter is the 
"regular" price that the consumer expects to pay for this product/service according to the reference he makes in his mind to a similar situation or experience of purchase. Payment decoupling separates the purchase of a product from its consumption in the mind of the consumer (p. 192, Thaler, 1999). This separation seems to reduce the perceived cost of the purchase and can be achieved through pre- (e.g. prepaid cards) or post- (e.g. credit cards) payment.

\section{THE FIELD STUDY}

This paper presents preliminary results of a field study of new mobile service use and adoption in Denmark. 36 mobile phone users from three categories: students at an affiliate university, employees at a public agency and employees within the Department of Informatics within our University, were included in the study. The average age of participants was 31 and $40 \%$ were females. Users were given new mobile phones and pre-paid SIM cards providing access to a wide variety of GPRS/WAP enabled content services. These services, available through the participating mobile operators' portal, provided access to information such as news, weather, local information and chatting functions. The purpose of the study was to observe the behavior of new mobile service users and the manner in which they accepted or rejected the use of the mobile services included in the study.

The project followed a mixed methods approach (Cresweli, 2003; Hammersley, 1996) and thus several qualitative and quantitative data was collected throughout the project period, which lasted from Noveraber 2004 to March 2005. The most prevalent forn of data collection was through surveys distributed to participants at various points throughout the project. Surveys included open ended and fixed response questions, based primarily on criteria from the combined UTAUT model of technology acceptance (Venkatesh et al., 2003). Data collection also included short interviews conducted with 17 participants at the close of the project. These followed an interview guide and were recorded and semi transcribed.

Once collected, data was analyzed through various means. From the interviews, topics which were frequently raised by participants were identified and extracted based on the queries to participants. These were compared to the results from the open ended responses included on the surveys to distill overlying themes across the project. The final set of topics raised were explored and analyzed according to the concepts of utility and pricing. In addition, participants' selections to the fixed response questions on the surveys were gathered and analyzed through a commercially available statistical survey analysis tool. 


\subsection{Results and Discussion}

We introduce the concept of mental accounting to elaborate on participants behaviors and attitudes towards mobile services based on the data collected from our field study. A key component of mental accounting is the consumers' reference price for the service under investigation. We observe from both interviews and survey data that participants related mobile services offered through the portal to the Internet services already available to them, as the following comment illustrates:

"Because I have access to a computer most of the times and those services are just as easy even easier to use on a regular computer..." (Male, 25, Interview Response)

This is further exemplified by participants' response in the surveys where $71 \%$ of the participants agreed or strongly agreed that the new mobile services did not offer anything new to what was already available to them through the Internet. The corresponding Internet services (i.e. news, weather forecast, map directories, chatting etc.) were typically perceived by participants as being free of charge. This could be explained by the fact that participants either had access to these services from work or school where their employer was paying for the Internet access or from home where the payment of the services is decoupled from the fixed monthly charges they pay for their Internet access.

This hau direct implications on participants' reference price for many of the mobile services offered through the mobile portai. In particular participants seemed to have a reference price that was mininal, close to zero. As one participant noted:

"... The problem with the mobile services is, that I have to pay for information, that has become commodities. Why pay for news, which is free on the internet? Why pay $2 \mathrm{kr}$ for a joke, when I can get thousands for free on the internet? I need something original and unique for a mobile service." (Male, 27, Survey Response)

Further, when participants were queried regarding the value of the new mobile services, $57 \%$ indicated that the mobile services available did not add value to their everyday life.

Consequently in terms of transactional utility, it seems that there was a negative effect in the use of mobile services because of their perceived high price. In particular, participants' perceived mobile services as expensive as compared to the perceived free of charge Internet services. Besides in terms of acquisitional utility, the mobile services were viewed as providing limited added value, generating low satisfaction because of poorer quality and speed 
as compared to those services already available to participants through other means:

"What the problem is that its like they have tried to take something from the Internet and put it down on a small screen instead of actually thinking, OK, what can we use this small screen for that is different than what is already on the Internet because when you can get something that you can get so much better while sitting with your laptop or something then there is no need sitting there with your phone, and waiting for it to come because its also very slow and the quality is not the same on that small screen" (Female, 26, Interview Response)

In turn these negative effects from both transactional and acquisitional utilities affected the participants' willingness to pay for the mobile services. Indeed, $62 \%$ of the participants indicated that the prices would be a barrier to the adoption of the mobile service offered.

Interestingly, the context of use of the mobile services was pointed to as an element impacting participants' willingness to adopt and use those services. Participants indicated that this context or physical location was one barrier to their mobile service use:

"what I like to use my phone for is when I am not close to the computer or the internet..." (Female, 33, Interview Response)

However, Participants seemed willing to pay and make use of the mobile services in certain circumstances (such as when there was a power outage and they were unable to access infornation through existing means). As some participants noted:

"I also tried to buy news and that was OK. But it was also a limited amount of news you got though and it was something I could see on my TV as well if I had text TV...one day 1 lost electricity in my house so I went on my phone instead and that kind of nice to have that opportunity" (Female, 26, Interview Response)

In these situations, participants did not have the ability to compare mobile services to the payment decoupled Internet services they typically had access to from work or their home environment. Therefore the mobile services use was perceived as value adding. It appears that the services offered through the mobile portal were only a 'back-up' when their typical means of access failed, or 'for fun' when they were traveling, etc. This indicates that the new mobile services need to be distinguished in some way, or be made to 'fit' users existing cognitive frame of how the services should function, what information they should provide and at what cost. 


\section{CONCLUSION}

While many consumers are purchasing new mobile phones with capabilities to access and use advanced mobile services, adoption of those services is still dwindling. Through the concept of mental accounting from the behavioral economics research domain, this paper has presented preliminary evidence towards the exploration of why consumers have not adopted advanced mobile services despite their availability. This paper suggests that existing technology acceptance research in the mobile industry should be extended to consider the mental accounting present in users actions related to the utility, pricing and value of new mobile services.

While existing technology adoption research has to some extent investigated the cognitive processes of consumers in the ongoing process of technology consumption, advanced mobile services offer a context of use which differs from many of the previous studies. Namely, mobile services in their current form are essentially substitutes for services already available through other means, such as the Internet. Thus while mobile services do provide information which many users desire and are accustomed to access on a daily and regular bases (such as news or weather), the use of the mobile as a device and service mechanism has not yet been defined in the cognitive processes of the users. This indicates that mobile operators must first define this context if advanced mobile services are going to be successfully adopted and diffused in the market.

Future research in this domain should expand on the resuits presented in this paper to further explore the behavioral and cognitive elements of users actions motivated through economic elements of choce. As of yet, limited work has been done to join the economic discipline and IS adoption studies in the mobile arena. We believe that bringing insights from both these strands of research is critical for a fuller understanding of the process in which users make decisions related to the adoption of new technologies to their everyday lives. There are time limits in everyone's day and while the television was successful in converting radio listeners' time into television viewing time, the same phenomenon has not yet occurred for advanced mobile services. Better understanding the economic motivations behind this non-adoption is critical if mobile operators are to reap the benefits they expect to gain from full scale deployment of those services. 


\section{ACKNOWLEDGEMENT}

This research was carried out in the realm of the Mobiconomy project at Copenhagen Business School. The research was in part supported by the Danish Research Agency, grant number \#2054-03-0004.

\section{References}

Ajzen, I. 1985. From Intentions to Actions: A Theory of Planned Behavior. In J. Kuhl, \& J. Beckman (Eds.), Action Control: From Cognition to Behavior. New York: Springer.

Ajzen, I. 1991. The Theory of Planned Behavior. Organizational Behavior and Human Decision Processes, 50: 179-211.

Ajzen, I., \& Fishbein, M. 1980. Understanding Attitudes and Predicting Social Behavior. New Jersey: Prentice Hall.

Blechar, J., Knutsen, L., \& Damsgaard, J. 2005. Reflexivity, the Social Actor and M-Service Domestication: Linking the Human, Technological, and Contextual. Paper presented at the IFIP TC8 WG 8.2 Working Conference on Designing Ubiquitous Information Environments: Socio-Technical Issues and Challenges, Cleveland, Ohio, USA.

Creswell, J. W. 2003. Research Design: Qualitative, Quantitative and Mixed Methods Approaches (second ed.). Thousand Oaks: Sage Publications.

Davis, F. D. 1989. Perceived Usefulness, Perceived Ease of Use, and User Acceptance of Information Technology. MIS Quarterly, 13: 319-339.

Hammersley, M. 1996. The Relationship Between Qualitative and Quantitative Research: Paradigm Loyalty Versus Methodological Eclecticism. In J. T. E. Richardson (Ed.), Handbook of Qualitative Research Methods for Psychology and the Social Sciences: 159174. London: The British Psychological Society.

Hung, S.-Y., ku, C.-Y., \& Chang, C.-M. 2003. Critical Factors of WÄP Service Adoption: An Emperical Study. Electronic Commerce Research and Applications, 2: 42-60.

Katz, M. L., \& Shapiro, C. 1992. Product introduction with network externalities. Journal of Industrial Economics, 40(1): 55-83.

Khalifa, M., \& Cheng, S. K. N. 2002. Adoption of Mobile Commerce: Role of Exposure. Paper presented at the 35th Hawaii International Conference on System Sciences (HICSS), Big Island, Hawaii.

Thaler, R. H. 1980. Towards a positive theory of consumer choice. Journal of Economic Behavior and Organization, 1: 39-60.

Thaler, R. H. 1985. Mental Accounting and Cosumer Choice. Marketing Science, 4: 199-214.

Thaler, R. H. 1999. Mental Accounting Matters. Journal of Behavioural Decision Making, 12: 183-206.

Venkatesh, V., Morris, M., Davis, G. B., \& Davis, F. D. 2003. User Acceptance of Information Technology: Towards a Unified View. MIS Quarterly, 27(3): 425-478. 